\title{
Adult pulmonary Langerhans cell histiocytosis might consist of two distinct groups: isolated form and extrapulmonary recidivism type
}

\author{
Jing Wang ${ }^{1,2 \#} \wedge$, Liwu Xie ${ }^{2 \#}$, Yuchun Miao ${ }^{3 \#}$, Xiaoyu Liu ${ }^{1}$, Yuan Tang ${ }^{1}$, Yanfeng Xi ${ }^{2}$, Jiang Chang ${ }^{2}$, \\ Yueqin $W \mathbf{u}^{2}$, Lili Jiang ${ }^{1}$
}

${ }^{1}$ Department of Pathology, West China Hospital of Sichuan University, Chengdu, China; ${ }^{2}$ Department of Pathology, Shanxi Tumor Hospital, Taiyuan, China; ${ }^{3}$ Department of Respiratory medicine, Shanxi Coal Central Hospital, Taiyuan, China

Contributions: (I) Conception and design: L Jiang; (II) Administrative support: Y Tang, X Liu; (III) Provision of study materials or patients: Y Miao, J Wang; (IV) Collection and assembly of data: J Wang; (V) Data analysis and interpretation: Y Xi, J Chang; (VI) Manuscript writing: All authors; (VII) Final approval of manuscript: All authors.

\#These authors contributed equally to this work.

Correspondence to: Lili Jiang. Department of Pathology, West China Hospital of Sichuan University, 37 Guoxue Alley, Chengdu 610041, China. Email: $879876047 @ q q . c o m$.

Background: Adult pulmonary Langerhans cell histiocytosis (PLCH) is a rare form of Langerhans cell histiocytosis (LCH) that typically occurs in cigarette smokers. The clinical course of PLCH is unpredictable; the disease may resolve spontaneously, or lead to multi-organ failure and death. To better understand this idiopathic disease, we retrospectively overviewed a cohort of Asian patients with PLCHs.

Methods: Herein, we have provided detailed clinicopathological features and molecular findings of PLCHs in a Southwestern Chinese population, including the expressions of apoptotic protein P16, programmed cell death 1 (PD-1), and programmed cell death-ligand 1 (PD-L1). Importantly, the $B R A F^{\mathrm{V} 600 \mathrm{E}}$ mutation was observed in this cohort.

Results: In accordance with the follow up data, the cohort was subdivided into two groups, an isolated pulmonary group and extrapulmonary recidivism group. Among the isolated group, the participants were predominantly young males ( $<40$ years old), with a history of smoking, respiratory symptoms (cough and difficulty breathing), showed more cystic lesions in computed tomography (CT) scanning, had more cellular Langerhans granulomas under the microscope, overexpression of P16 (66.7\%), high PD-1 (100\%) and low PD-L1 (33.3\%) expressions, and no $B R A F^{\mathrm{V} 600 \mathrm{E}}$ mutation was detected. In contrast, the extrapulmonary recidivism group showed significantly older age ( $>40$ years old), recurrent spontaneous pneumothorax, more nodular changes in CT scanning, more interstitial fibrosis histologically, expression rates of $100 \%$ of P16, $66.7 \%$ of PD-1, and $33.3 \%$ of PD-L1; and importantly, $B R A F^{\mathrm{V} 600 \mathrm{E}}$ mutation was detected in $33.3 \%$ of this subdivision.

Conclusions: We found that adult PLCH might consist of two distinct groups: an isolated form and extrapulmonary recidivism PLCH. Overexpression of P16 could be a diagnostic biomarker for PLCH. An extremely low mutation rate of the $B R A F$ gene in adult PLCH in our cohort indicated that there might be other pathogeneses for this disease among Asian patients.

Keywords: Pulmonary Langerhans cell histiocytosis (PLCH); P16; PD-L1; PD-1; BRAF ${ }^{\mathrm{V} 600 \mathrm{E}}$

Submitted Oct 30, 2020. Accepted for publication Jan 26, 2021.

doi: $10.21037 / \mathrm{atm}-20-8141$

View this article at: http://dx.doi.org/10.21037/atm-20-8141

\footnotetext{
$\wedge$ ORCID: 0000-0002-7359-7739.
} 


\section{Introduction}

Langerhans cell histiocytosis ( $\mathrm{LCH})$ is an abnormal proliferation of Langerhans-type cells with specific expression of CD1a, langerin (CD207), and S100 proteins. It can affect people of all ages, but occurs more commonly in children (1). Pulmonary Langerhans cell histiocytosis (PLCH) is a different form of LCH that typically occurs in the lungs of adult cigarette smokers. The clinical course of PLCH is highly variable and often unpredictable; the disease may resolve spontaneously (more often in young smokers), or lead to multi-organ failure and death (2). Therefore, it is still unclear whether PLCH is a neoplastic entity or reactive process of Langerhans cells.

Previous studies have suggested that $\mathrm{LCH}$ is a dendritic cell neoplasm, with the prevalence of $B R A F^{\mathrm{V} 600 \mathrm{E}}$ mutation ranging from $36-64 \%$ in the Western population, including in PLCH (3-5). However, the pathogenesis of PLCH remains unclear, especially in Asian patients. In this study, we aimed to gather and present some molecular findings of PLCHs in a Southwest China population, including the expressions of apoptotic protein $\mathrm{P} 16$, programmed cell death 1 (PD-1), and programmed cell death-ligand 1 (PD-L1). Notably, the $B R A F^{\mathrm{V} 600 \mathrm{E}}$ mutation was observed and reported on in this cohort.

We present the following article in accordance with the MDAR checklist (available at http://dx.doi.org/10.21037/ atm-20-8141).

\section{Methods}

\section{Participants and collection of samples}

A retrospective study was conducted drawing from the archive of the West China Hospital of Sichuan University between January 2014 and December 2019. Due to the lack of demonstrable Langerhans cells in old fibrotic lesions, we selected 6 early (cellular) PLCH cases. All 6 adult PLCH participants had undergone fiberoptic bronchoscopic biopsy or surgical resection, followed by formalin-fixed paraffin-embedded (FFPE) tissue formation. All cases met the criteria of PLCH according to the 2015 World Health Organization (WHO) classification of tumors of the lung, pleura, thymus, and heart. The study was conducted in accordance with the Declaration of Helsinki (as revised in 2013). Written informed consent was provided by all participants included in the analysis. This study was approved by the Ethical Committee of the West China Hospital (No. 2020-1211).
All clinical data were retrospectively collected from the database of the hospital information system, including symptoms and signs, smoking habits, history of present and past illness, laboratory examinations, chest computed tomography (CT) examinations and lung function tests, as well as any systemic treatments that had been administered. All participants were followed up, 3 cases were identified as PLCH accompanied by extrapulmonary involvement (extrapulmonary recidivism group, $3 / 6,50 \%$ ), and the others were allocated to the isolated pulmonary group $(3 / 6$, $50 \%)$.

\section{Immunobistochemistry (IHC)}

According to manufacturer's instructions, IHC was performed using an automated IHC instrument (Roche Diagnostics, Basel, Switzerland) using the antibodies of P16 (clone 1C1, ZSGB Biotechnology Co. Ltd., Beijing, China), PD-1 (clone UMAB199, ZSGB Biotechnology Co. Ltd., Beijing, China), and PD-L1 (clone 22C3, Dako, Glostrup, Denmark). Antibodies against CD1a (clone O10, Dako, Glostrup, Denmark), langerin (clone 12D6, Maixin Biotechnology Development Co. Ltd., Fuzhou, China), S100 (clone 4C4.9, Maixin Biotechnology Development Co. Ltd., Fuzhou, China) were used for IHC to determine the immunophenotype of the PLCH.

The positive staining of PD-1 and PD-L1 were interpreted and scored by two experienced pathologists. Cases were scored as positive for PD-1 if any of the tumor immune cells stained positive in either a membrane or membrane/cytoplasmic pattern as previously reported (3-5). The criteria for scoring PD-L1 was referred to tumor proportion score (TPS) on non-small cell lung cancer (NSCLC) according to the manufacturer's instruction. A TPS $<1 \%$ was defined as negative, whereas TPS $1-49 \%$ was defined as low expression, and TPS $\geq 50 \%$ as high expression.

\section{Detection of the genomic BRAF ${ }^{V 600 E}$ mutation}

Extraction of DNA was performed using a QIAamp DNA formalin fixed paraffin-embedded (FFPE) Tissue Kit (Qiagen, Hilden, Germany), according to the manufacturer's instructions. After quality control, all DNA samples were genotyped for the presence of $B R A F^{\mathrm{V} 600 \mathrm{E}}$ mutation using a commercial human $B R A F$ gene V600E mutation detection kit [fluorescence polymerase chain reaction (PCR) method, SLAN-965 Real-Time PCR System] of AmoyDx 
Table 1 Clinical features of two groups of adult PLCH

\begin{tabular}{|c|c|c|c|c|c|c|}
\hline Case & \multicolumn{3}{|c|}{ Isolated pulmonary group } & \multicolumn{3}{|c|}{ Extrapulmonary recidivism group } \\
\hline Gender & M & M & M & $\mathrm{F}$ & M & M \\
\hline Age (years) & 20 & 24 & 35 & 53 & 42 & 64 \\
\hline $\begin{array}{l}\text { Clinical } \\
\text { manifestations }\end{array}$ & $\begin{array}{c}\text { Cough and difficulty } \\
\text { breathing, bilateral } \\
\text { pneumothorax }\end{array}$ & Cough, sputum & $\begin{array}{l}\text { Cough, sputum, } \\
\text { difficulty } \\
\text { breathing }\end{array}$ & $\begin{array}{c}\text { Recurrent } \\
\text { spontaneous } \\
\text { pneumothorax }\end{array}$ & Chest pain & Chest pain \\
\hline $\begin{array}{l}\text { Smoking } \\
\text { (number per day, years) }\end{array}$ & 20,7 & $3,0.5$ & NA & 0 & 20,20 & 40,40 \\
\hline CT scan & $\begin{array}{c}\text { Thin-walled cysts, } \\
\text { bilateral } \\
\text { pneumothorax }\end{array}$ & $\begin{array}{l}\text { Thin-walled cysts, } \\
\text { micro-nodules } \\
(<0.3 \mathrm{~cm})\end{array}$ & $\begin{array}{c}\text { Big-nodules, } \\
\text { partial cystic } \\
\text { changes }\end{array}$ & $\begin{array}{l}\text { Thin-walled } \\
\text { cysts, nodules } \\
(0.1-0.8 \mathrm{~cm})\end{array}$ & $\begin{array}{l}\text { Nodules } \\
(0.3-1 \mathrm{~cm})\end{array}$ & $\begin{array}{c}\text { Nodules }(<1 \mathrm{~cm}), \\
\text { central cystic change }\end{array}$ \\
\hline Underlying disease & No & No & Aml & Ptc, Scid & No & No \\
\hline Treatment & Sc, Op 3 month & Sc & Cvp 3 cycles & $\begin{array}{l}\text { Thymalfasin, } \\
2 \text { months (t1w) }\end{array}$ & Sc & $\begin{array}{c}\text { Etoposide } 15 \text { cycles ( } q 1 w) \\
\text { Ecop } 3 \text { cycles ( } q 4 w)\end{array}$ \\
\hline Follow-up (months) & 35 & 7 & 8 & 38 & 46 & 19 \\
\hline Prognosis & Alive & Alive & Dead & Alive & Dead & Alive \\
\hline
\end{tabular}

PLCH, pulmonary Langerhans cell histiocytosis; F, female; M, male; NA, not available; AML, acute mononuclear leukemia; PTC, papillary thyroid carcinoma; SCID, severe combination of immunodeficiency; OP, oral prednisone; SC, smoking cessation; CVP, cyclophosphamide, vincristine and prednisone; t1w, two times per weeks; q1w, one time per week; q4w, one time per four weeks; ECOP, etoposide, cyclophosphamide, vincristine, predniso.

biomedical technology co. Ltd. (Guangxi, China).

\section{Statistical analysis}

Fisher's exact test were used to estimate the association of $B R A F^{\mathrm{V} 600 \mathrm{E}}$ mutations and PD-1, PD-L1, P16 expression with the clinical characteristics and the results of PLCH.

Statistical analyses were performed using IBM SPSS Statistics 19 software. $\mathrm{P}$ values of 0.05 were considered as statistically significant.

\section{Results}

\section{Clinical features}

The relevant clinical characteristics of this study are summarized in Table 1. As mentioned before, 3 participants $(50 \%)$ presented with isolated pulmonary lesions, and the other 3 showed extrapulmonary involvement during follow up. Accordingly, this cohort was subdivided into two groups, the isolated pulmonary group, and extrapulmonary recidivism group. The most common areas of extrapulmonary involvement were the ribs $(2 / 3$, $66.7 \%$ ), with other areas including the pituitary gland, skin, and thyroid gland. The age range of all cases was 20 to 64 years, with a median age of 38.5 years old. Interestingly, all isolated form cases were $<40$ [20-35] years old, while extrapulmonary recidivism group participants were $>40$ [42-64] years old. Furthermore, the gender predilection was prominent, with males constituting $86.7 \%$ (5/6).

With the exception of case $3,100 \%$ of isolated PLCHs had a history of smoking, while $66.7 \%$ of extrapulmonary PLCHs had a severe smoking habit. Among the isolated pulmonary group, all participants presented with respiratory symptoms, including cough and difficulty breathing. Spontaneous pneumothorax accompanied $33.3 \%$ of cases. In contrast, $66.7 \%$ of extrapulmonary recidivism patients presented with chest pain rather than respiratory symptoms. Consistent with the isolated form, $33.3 \%$ of extrapulmonary patients had recurrent pneumothorax. 

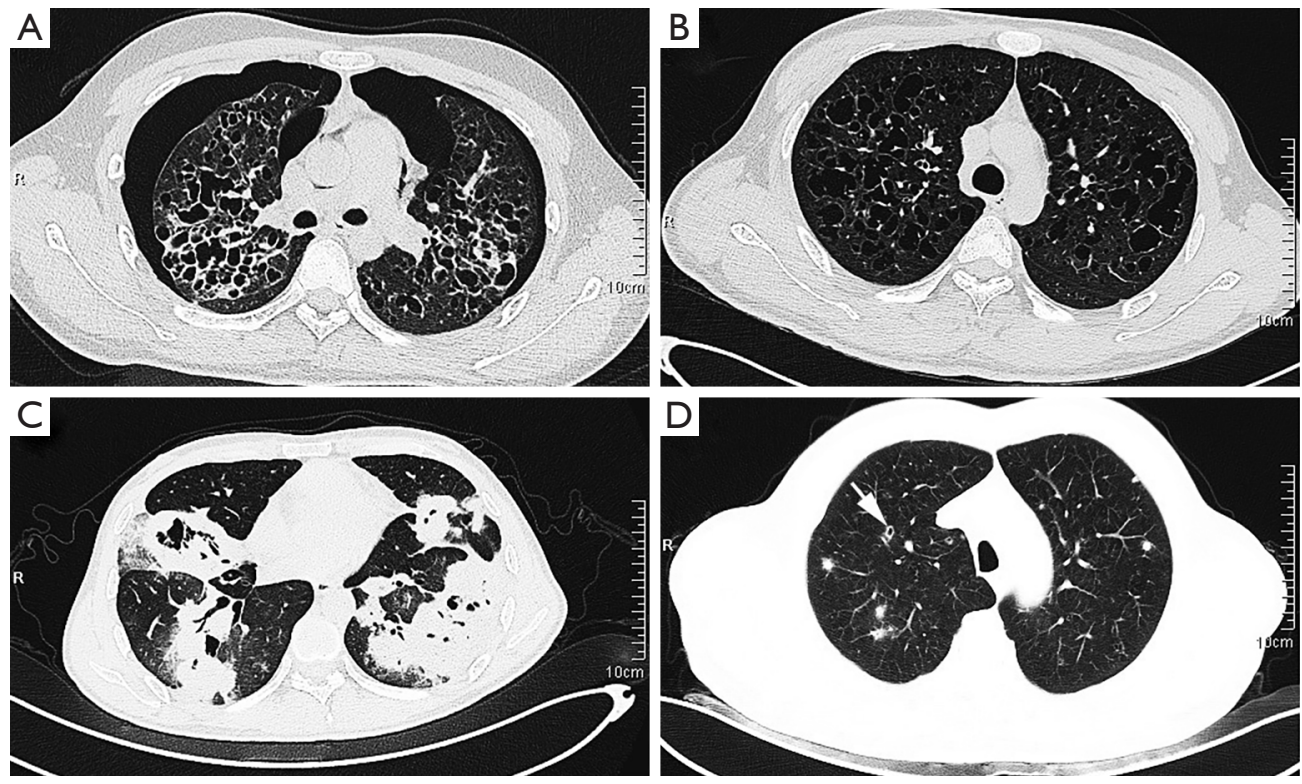

Figure $1 \mathrm{CT}$ scanning showed that the isolated lung group presented more cystic lesions, including thin-walled cysts accompanied with bilateral pneumothorax (A, case 1), cysts of variable size with small nodules (B, case 2), and thick-walled cysts with multiple masses (C, case 3). Extrapulmonary recidivism (D, case 6) presented poorly defined nodules, with central lucency indicating developing cysts (arrow). CT, computed tomography.

In terms of imaging, $100 \%$ of isolated PLCHs showed cystic lesions, whereas $100 \%$ of extrapulmonary PLCH participants presented nodular-type lesions. Additionally, $66.7 \%$ of isolated PLCHs was observed to have nodules of variable size. Precisely, case 1 showed thin-walled cavities with different sizes in both lungs, a widened lung septum, and bilateral pneumothorax (Figure 1A). Case 2 presented multiple thin-walled cysts in both lungs, especially in the upper lobe, and small nodules $(<0.3 \mathrm{~cm})$ in the lower lobe of the right lung (Figure 1B). Case 3 presented multiple large nodules with cystic changes in both lungs (Figure 1C). However, all extrapulmonary PLCHs were found to have multiple nodules $<1 \mathrm{~cm}$ in diameter. Only $33.3 \%$ of cases showed thin-walled cysts which had initially been reported as pulmonary bullae (case 4). Interestingly, case 6 showed some nodules had a central lucency (Figure 1D), indicating the transformation process from nodule to cyst.

However, a third of participants presented with accompanying underlying disease in both groups of adult PLCHs. A participant from the isolated pulmonary group was suffering acute mononuclear leukemia (case 3), and a participant from the extrapulmonary recidivism group also had thyroid papillary carcinoma, hepatitis B, and a severe combination of immunodeficiency (case 4).

As adult PLCH is a rare disease, and its therapeutic strategy is still controversial, various treatments were received by our participants. Smokers were all treated to assist in the cessation of smoking, and this was an exclusive management for $66.7 \%$ of participants. Cases 2 and 5 were successfully managed with smoking cessation. Unfortunately, case 5 died of multi-systemic involvement 46 months later. The other $33.3 \%$ of participants received various medications, including oral prednisone for 3 months (case 1), 15 cycles of etoposide, and 3 cycles of ECOP (case 6). Both case 1 and 6 survived (35 and 19 months). The remaining $33.3 \%$ of participants were treated with medication for their underlying diseases, including 3 cycles of cyclophosphamide, vincristine, prednisone (CVP) for acute mononuclear leukemia (case 3) and thymalfasin 2 months for hepatitis B (case 4). Participant 3 died of leukemia 8 months later. We found that the prognosis of the isolated lung group ( $<40$ years) was significantly better than that of the extrapulmonary invasion group ( $>40$ years).

\section{Histological findings}

Consistent with CT imaging, all adult PLCH participants showed either nodular (Figure $2 A$ ) or cystic lesions (Figure $2 B$ ) at low magnification. Among the isolated PLCH group, $66.7 \%$ presented cysts of variable sizes 

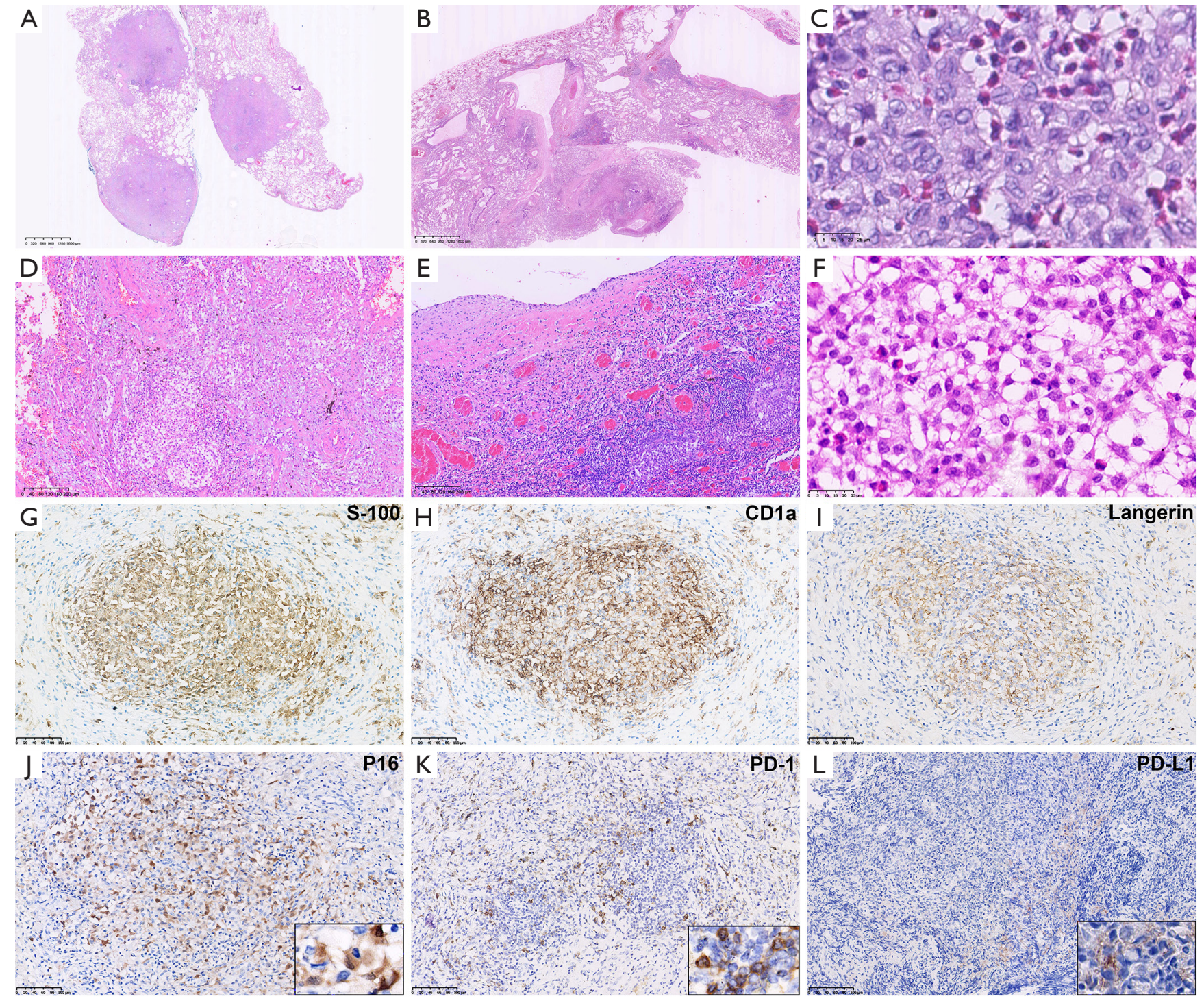

Figure 2 Microscopic pathological features of Adult PLCHs. Adult PLCHs showed either nodular Roche automatic immunohistochemical staining (A) or cystic lesions (B) at low magnification (HE, magnification $\times 12.5$ ). Commonly, Langerhans cells clustered around the bronchioles and destroyed the bronchial wall, but were recognized by presence of small artery. In the cystic lesions, Langerhans cells accumulated in the walls of variable-sized cysts. (C) High magnification revealed Langerhans cells with unclear cell boundaries, irregular nuclear membranes, visible furrows, and moderate amounts of slightly eosinophilic cytoplasm (HE, magnification $\times 800)$. The extrapulmonary recidivism group presented more significant interstitial fibrosis either in nodular (D) or cystic (E) (HE, magnification $\times 100)$, combined with infiltration by numerous eosinophils, lymphocytes, and plasma cells. (F) Extrapulmonary involvement was demonstrated by rib invasion presenting with infiltration of Langerhans cells between trabeculae (HE, magnification $\times 100)$. Traditional diagnostic markers, S100, langerin, and CD1a were positive in all 6 cases, which confirmed the diagnosis (EnVision, G,H,I, magnification $\times 200$ ). (J) P16 was overexpressed in Langerhans cells with a cytoplasm positive pattern (EnVision, magnification $\times 200)$. Adult PLCH was found to have high PD-1 (K) expression in tumor immune cells and low PD-L1 (L) expression in Langerhans cells (EnVision, magnification $\times 200)$. PLCH, pulmonary Langerhans cell histiocytosis; PD-1, programmed cell death 1; PD-L1, programmed cell death-ligand 1. 
Table 2 Overview of P16, PD-1, PD-L1 expressions and $B R A F^{\mathrm{V} 600 \mathrm{E}}$ mutation of PLCH

\begin{tabular}{|c|c|c|c|c|c|c|}
\hline \multirow{2}{*}{ Case } & \multicolumn{3}{|c|}{ Isolated pulmonary group } & \multicolumn{3}{|c|}{ Extrapulmonary recidivism group } \\
\hline & 1 & 2 & 3 & 4 & 5 & 6 \\
\hline P16 & + & + & - & + & + & + \\
\hline PD-1 & $5 \%$ & $20 \%$ & $10 \%$ & - & $10 \%$ & $10 \%$ \\
\hline PD-L1 & - & - & $5 \%$ & - & $5 \%$ & - \\
\hline$B R A F^{\mathrm{V} 600 \mathrm{E}}$ mutation & - & - & - & - & - & + \\
\hline
\end{tabular}

PD-1, programmed cell death 1; PD-L1, programmed cell death-ligand 1; PLCH, pulmonary Langerhans cell histiocytosis.

(Figure 2B) and cellular Langerhans cells were aggregated within the cyst walls without obvious fibrosis (Figure 2C). In contrast, all cases in the extrapulmonary invasion group showed significant interstitial fibrosis (Figure 2D,E,F) and well-circumscribed nodular granulomas were present in 66.7\% cases. Nevertheless, a cluster of Langerhans cells was the diagnostic criteria for PLCH, which was always mixed with variable numbers of eosinophils, plasma cells, and lymphocytes. Adjacent alveolar spaces were commonly filled with pigmented macrophages (smoker's macrophages). The characteristics of Langerhans cells were consistent with previous reports, including unclear cell boundaries, irregular nuclear membranes, and visible furrows, as well as moderate amounts of pale or slightly eosinophilic cytoplasm.

\section{Imтипорhenotype}

As traditional diagnostic markers, S100, langerin, and CD1a were positive in all 6 cases resulting in a sensitivity of $100 \%$ (Figure 2G,H,I). Testing for apoptotic protein P16 and the immune checkpoint markers, PD-1 and PD-L1, were also performed on our cohort (Table 2).

In total, up to $83.3 \%$ of cases showed diffuse nuclear and cytoplasmic staining of P16 in Langerhans cells (Figure 27). Expression of P16 was detected in $66.7 \%$ of participants in the isolated pulmonary group, and $100 \%$ of participants in the extrapulmonary recidivism group showed P16 expression.

The IHC staining of PD-1 was localized to the membranes of tumor infiltrating lymphocytes (Figure $2 \mathrm{~K}$ ). The results illustrated that $\mathrm{PD}-1$ was positive in all 3 isolated PLCHs (100\%), and $66.7 \%$ of the 3 extrapulmonary PLCHs. Furthermore, PD-1 was lowlyexpressed in all cases of expression, ranging from $5 \%$ to $20 \%$. On the other hand, the Langerhans cells were negative for PD-1 in all cases.
While PD-1 staining was generally easy to interpret, PD-L1 was potentially more complicated as it stained in both the Langerhans cells and normal pigmented macrophages (a variety of histiocytes). With the help of expressions for langerin, CD1a, and S-100, low expression (TPS $5 \%$ ) of PD-L1 (22C3) was identified in only $33.3 \%$ of participants with membrane patterns (Figure $2 L$ ). There was no statistically significant difference between the isolated pulmonary group and extrapulmonary recidivism group.

Statistical tests showed no significant correlation between the expressions of P16, PD-1, PD-L1, and various other clinical parameters.

\section{BRAF ${ }^{V 600 E}$ mutation}

Mutation analysis for $B R A F^{\mathrm{V} 600 \mathrm{E}}$ was performed in all 6 participants. Negative, positive, and internal controls were set up for each sample. Finally, $B R A F^{\mathrm{V} 600 \mathrm{E}}$ mutation was identified in only a single participant (case 6, 16.7\%). Amongst our limited cases, all isolated PLCHs showed the wild type on $B R A F^{\mathrm{V} 600 \mathrm{E}}$ gene, whereas $33.3 \%$ of the extrapulmonary PLCHs presented $B R A F^{\mathrm{V} 600 \mathrm{E}}$ mutations. Statistical tests showed no significant correlation between the $B R A F^{\mathrm{V} 600 \mathrm{E}}$ mutation and age, gender, extrapulmonary progression, and results.

\section{Discussion}

A retrospective study by Vassallo et al. found that PLCH occurs with equal frequency in both genders (6). Unlike previous reports, there was an obvious gender trend in our cohort, with men accounting for $83.3 \%$ of the total sample. This may be due to the much lower number of Asian females who smoke, which is an important factor in PLCH; the link between smoking and PLCH has been clearly substantiated. In our and previous studies (7), $>80 \%$ 
of participants had a history of smoking. In addition, 50\% of our cases developed extrapulmonary recidivism during the progression of the disease, which is much higher than previously reported (approximately 15\%). Accordingly, we allocated the participants to two groups, the isolated pulmonary group and the extrapulmonary recidivism group, and some distinguishing features between the two groups were found.

First, significant differences in age were found between the two groups; the age of the extrapulmonary recidivism group ( $>40$ years old) was significantly greater than that of the isolated lung group ( $<40$ years old). This age-related parameter was also observed in a recent retrospective study (8), in which older age was found to be associated with poor prognosis. Second, in terms of clinical symptoms, the isolated pulmonary group displayed more respiratory symptoms (cough and difficulty breathing), while the extrapulmonary recidivism group showed a higher rate of recurrent spontaneous pneumothorax and chest pain. Third, CT scan revealed that the isolated lung group had more cystic lesions, whereas the extrapulmonary recidivism group showed more nodular lesions. For histopathology, cellular Langerhans granulomas were more common in the isolated lung group, indicating the early/proliferation phase. The extrapulmonary recidivism group presented more interstitial fibrosis accompanied by chronic inflammatory cell infiltration, alveolar epithelial hyperplasia, larger number of infiltrating macrophages, and decreased Langerhans cells, which suggested the late/receding phase. Further research is required to establish whether these phenomena relate to the disease pathogenesis and progression.

There were some interesting features in present cohort. Case 3 in the isolated pulmonary group was a 35-year-old male patient with acute mononuclear leukemia, and this combination had not been reported previously. Case 4 in the extrapulmonary recidivism group was the only female patient in this group, did not smoke, but presented with the combined co-morbidities of severe immunodeficiency and low $\mathrm{T}$ and B cell counts. She was diagnosed with thyroid gland LCH and papillary thyroid cancer two years after her initial diagnosis. It is well known that thyroid papillary carcinoma is closely related to $B R A F^{\mathrm{V} 600 \mathrm{E}}$ mutation (9), which is a common gene alteration in LCH. However, in case 4 , we did not detect $B R A F^{\mathrm{V} 600 \mathrm{E}}$ mutation when investigating her PLCH. Further research is required to explore whether $B R A F^{\mathrm{V} 600 \mathrm{E}}$ mutation or the activation of related pathways promote thyroid cancer and PLCH simultaneously.
Several studies have shown that tobacco smoke could promote dendritic cell survival by anti-apoptotic mechanisms and that $\mathrm{P} 16$ negatively regulates the course of the cell cycle by inhibiting the activity of cyclin D/ CDK (Figure 3) (10,11); accordingly, we selected apoptosis associated protein P16 to evaluate the status. In our study, the positive rate of $\mathrm{P} 16$ was up to $86.7 \%$, suggesting that it was highly sensitive to PLCH. Hence, we proposed P16 could be a diagnostic biomarker for PLCH. Moreover, the overexpression of $\mathrm{P} 16$ protein may be related to the regulation of the cell cycle, resulting in the pathogenesis of PLCH. Again, P16 was overexpressed in $66.7 \%$ of participants in the isolated pulmonary group and $100 \%$ in the extrapulmonary recidivism group, respectively. There was no significant correlation between P16 activity and the progression of $\mathrm{PLCH}$, which opposed the data of Chilosi et al., who found that P16 was not expressed in all invasive PLCHs, suggesting that loss of senescence control may be related to the clinical invasiveness of PLCH (12).

Another characteristic of our results was high PD-1 $(83.3 \%)$ and low PD-L1 (33.3\%) expressions. This is consistent with the report of $\mathrm{Xu}$ et al., who found $1 / 6$ (16.7\%) of PLCH patients expressed PD-L1 (13). In recent years, PD-1 and PD-L1 inhibitors have successively entered the clinic and have shown promising results (14). However, the application of PD-1 inhibitors and PD-L1 inhibitors in PLCH has not yet been reported. Our results of high PD-1 expression support the potential use of PD-1 inhibitors in refractory PLCH.

Various upstream somatic mutations of the mitogenic activated protein kinase (MAPK) pathway might play a role in LCH $(3,15-17)$. The $B R A F$ gene is a serine/suferanine kinase involving signal transmission in the MAPK pathway, and its mutation has been found in PLCH at a rate of 3664\% (3,18-20). Breaking traditional perspective, the present study showed significantly lower rate of $B R A F^{\mathrm{V} 600 \mathrm{E}}$ mutation $(16.7 \%$, case 6$)$ in PLCH than previously reported. The impact of specific $B R A F^{\mathrm{V} 600 \mathrm{E}}$ mutations on the clinical course of PLCH is uncertain. There is little data on the clinical significance of this clonal molecular alteration in adult PLCH, except in the study of pediatric systemic LCH (21). Berres et al. demonstrated an association between the presence of $B R A F^{\mathrm{V} 600 \mathrm{E}}$ mutation and the chance of highrisk disease and resistance to first-line therapy, but did not find that it affected survival in pediatric LCH. In our study, we observed that $B R A F^{\mathrm{V} 600 \mathrm{E}}$ mutation occurred in one extrapulmonary involvement case, but this was without statistical significance. Further studies are anticipated to 


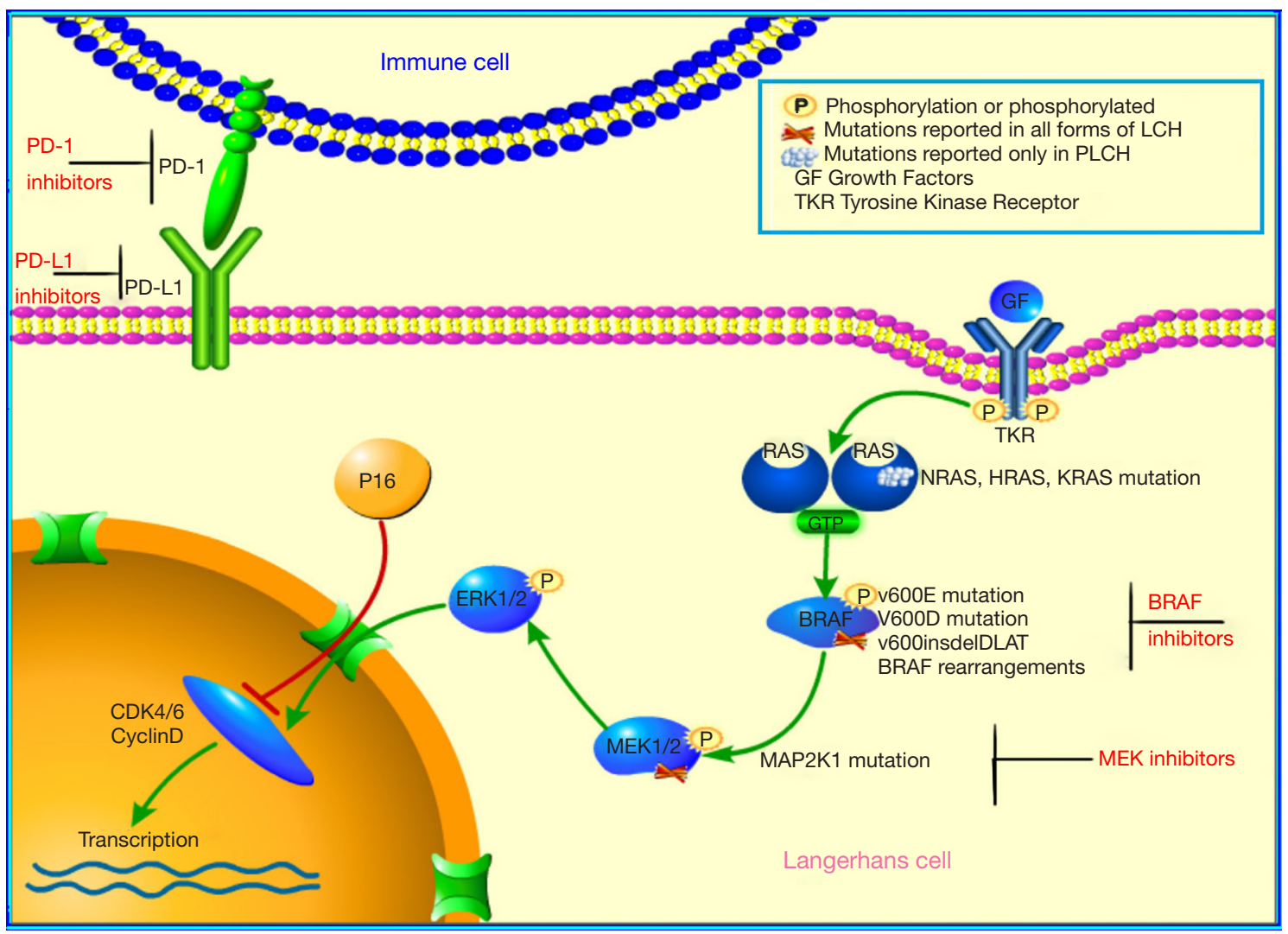

Figure 3 Schematic diagram of MEK-ERK signal cascade of the MAPK pathway, PD-1 and PD-L1 pathway, and P16 inhibitory pathway. MEK-ERK, Ras-Raf- mitogen-activated protein kinase-extracellular-signal-regulated kinase; MAPK, mitogen-activated protein kinase; PD1 , programmed cell death 1 ; PD-L1, programmed cell death-ligand 1 .

assess the effects of $B R A F^{\mathrm{V} 600 \mathrm{E}}$ mutation on adult PLCH, and to determine whether this mutation is useful for disease stratification and prediction.

The treatment of PLCH is generally conducted based on the extent of disease and clinical course. As a localized disease, PLCH often spontaneously resolves in young patients. Except for the cessation of smoking, no pharmacologic intervention is needed. The use of corticosteroids and/or chemotherapy drug therapy, including cladribine, vinblastine, methotrexate, cyclophosphamide, and etoposide should be considered for patients with severe or progressive disease (22). In our study, only one patient with extrapulmonary progression received chemotherapy, but the effect was not significant. The discovery of the $B R A F^{\mathrm{V} 600 \mathrm{E}}$ mutation in PLCH lead to the possibility of targeted therapy using BRAF inhibitors (e.g., vemurafenib, dabrafenib), which were originally developed for the treatment of melanoma and other malignancies (23). However, these treatments need to be critically evaluated due to their potentially serious side effects.

Herein, we proposed that adult PLCH might harbor two groups, and the prognosis of the isolated lung group ( $<40$ years) was significantly better than that of the extrapulmonary invasion group ( $>40$ years).

\section{Conclusions}

Adult PLCH is a rare disease that includes a wide range of clinical manifestations. We proposed that PLCH might entail two distinct groups: the isolated form and the extrapulmonary recidivism PLCH, as we found some significant differences between the two groups. Our high PD-1 expression results provide the possibility for the application of PD-1 inhibitors in refractory PLCH. Over expression of $\mathrm{P} 16$ could be a diagnostic biomarker for PLCH. The extremely low mutation rate of the $B R A F^{\mathrm{V} 600 \mathrm{E}}$ gene in adult PLCH in our cohort indicated that there might be other pathogeneses in for this disease among the 
Asian population.

\section{Acknowledgments}

Funding: This work was supported by Sichuan Science and Technology Program (grant number 2020YFS0275) and 1.3.5 Project for Disciplines of Excellence-clinical research Incubation Project, West China Hospital, Sichuan University (No. 2019HXFH002).

\section{Footnote}

Reporting Checklist: The authors have completed the MDAR checklist. Available at http://dx.doi.org/10.21037/atm-208141

Data Sharing Statement: Available at http://dx.doi. org/10.21037/atm-20-8141

Conflicts of Interest: All authors have completed the ICMJE uniform disclosure form (available at http://dx.doi. org/10.21037/atm-20-8141). The authors have no conflicts of interest to declare.

Ethical Statement: The authors are accountable for all aspects of the work in ensuring that questions related to the accuracy or integrity of any part of the work are appropriately investigated and resolved. The study was conducted in accordance with the Declaration of Helsinki (as revised in 2013). The study was approved by the West China Hospital of Sichuan University (No. 2020-1211). Written informed consent was provided by all participants.

Open Access Statement: This is an Open Access article distributed in accordance with the Creative Commons Attribution-NonCommercial-NoDerivs 4.0 International License (CC BY-NC-ND 4.0), which permits the noncommercial replication and distribution of the article with the strict proviso that no changes or edits are made and the original work is properly cited (including links to both the formal publication through the relevant DOI and the license). See: https://creativecommons.org/licenses/by-nc-nd/4.0/.

\section{References}

1. Swerdlow SH, Campo E, Harris NL, et al. WHO Classification of Tumours of Haematopoietic and Lymphoid Tissues. WHO Classification of Tumours,
Revised 4th Edition, Volume 2, 2017.

2. Allen CE, Ladisch S, McClain KL. How I treat Langerhans cell histiocytosis. Blood 2015;126:26-35.

3. Kamionek M, Ahmadi-Moghaddam P, Sakhdari A, et al. Mutually exclusive extracellular signal-regulated kinase pathway mutations are present in different stages of multi-focal pulmonary Langerhans cell histiocytosis supporting clonal nature of the disease. Histopathology 2016;69:499-509.

4. Torre O, Elia D, Caminati A, et al. New insights in lymphangioleiomyomatosis and pulmonary Langerhans cell histiocytosis. Eur Respir Rev 2017;26:170042.

5. Roden AC, Hu X, Kip S, et al. BRAF V600E expression in Langerhans cell histiocytosis: clinical and immunohistochemical study on 25 pulmonary and 54 extrapulmonary cases. Am J Surg Pathol 2014;38:548-51.

6. Vassallo R, Ryu JH, Schroeder DR, et al. Clinical outcomes of pulmonary Langerhans'-cell histiocytosis in adults. N Engl J Med 2002;346:484-90.

7. Mogulkoc N, Veral A, Bishop PW, et al. Pulmonary Langerhans' Cell Histiocytosis: Radiologic Resolution Following Smoking Cessation. Chest 1999;115:1452-5.

8. Harmon CM, Brown N. Langerhans Cell Histiocytosis: A Clinicopathologic Review and Molecular Pathogenetic Update. Arch Pathol Lab Med 2015;139:1211-4.

9. Wang Z, Sun K, Jing C, et al. Comparison of droplet digital PCR and direct Sanger sequencing for the detection of the BRAFV600E mutation in papillary thyroid carcinoma. J Clin Lab Anal 2019;33:e22902.

10. Sharma G, Mirza S, Prasad CP, et al. Promoter hypermethylation of p16INK4A, p14ARF, CyclinD2 and Slit2 in serum and tumor DNA from breast cancer patients. Life Sci 2007;80:1873-81.

11. Marchal J, Kambouchner M, Tazi A, et al. Expression of apoptosis-regulatory proteins in lesions of pulmonary Langerhans cell histiocytosis. Histopathology 2004;45:20-8.

12. Chilosi M, Facchetti F, Caliò A, et al. Oncogene-induced senescence distinguishes indolent from aggressive forms of pulmonary and non-pulmonary Langerhans cell histiocytosis. Leuk Lymphoma 2014;55:2620-6.

13. Xu J, Sun HH, Fletcher CD, et al. Expression of Programmed Cell Death 1 Ligands (PD-L1 and PD-L2) in Histiocytic and Dendritic Cell Disorders. Am J Surg Pathol 2016;40:443-53.

14. BBrahmer JR, Tykodi SS, Chow LQ, et al. Safety and activity of anti-PD-L1 antibody in patients with advanced cancer. N Engl J Med 2012;366:2455-65. 
15. Nelson DS, van Halteren A, Quispel WT, et al. MAP2K1 and MAP3K1 mutations in Langerhans cell histiocytosis. Genes Chromosomes Cancer 2015;54:361-8.

16. Alayed. K, Medeiros. LJ, Patel. KP, et al. BRAF and MAP2K1 mutations in Langerhans cell histiocytosis: a study of 50 cases. Hum Pathol 2016;52:61-7.

17. Liu. H, Osterburg. AR, Flury. J, et al. MAPK mutations and cigarette smoke promote the pathogenesis of pulmonary Langerhans cell histiocytosis. JCI Insight 2020;5:e132048.

18. Jouenne F, Chevret S, Bugnet E, et al. Genetic Landscape of Adult Langerhans Cell Histiocytosis with Lung Involvement. Eur Respir J 2020;55:1901190.

19. Zhang L, Pacheco-Rodriguez G, Steagall WK, et al. BRAF and NRAS mutations in circulating Langerhanslike CD1a+ cells in a patient with pulmonary Langerhans' cell histiocytosis. Eur Respir J 2017;50:1700521.

Cite this article as: Wang J, Xie L, Miao Y, Liu X, Tang Y, Xi Y, Chang J, Wu Y, Jiang L. Adult pulmonary Langerhans cell histiocytosis might consist of two distinct groups: isolated form and extrapulmonary recidivism type. Ann Transl Med 2021;9(4):357. doi: 10.21037/atm-20-8141
20. Pors J, Churg A. Cyclin D1 and BRAF V600E immunohistochemical staining in pulmonary Langerhans cell histiocytosis. Histopathology 2020;76:1091-3.

21. Berres ML, Lim KPH, Peters T, et al. BRAF-V600E expression in precursor versus differentiated dendritic cells defines clinically distinct LCH risk groups. J Exp Med 2015;212:281.

22. Vassallo R, Harari S, Tazi A. Current understanding and management of pulmonary Langerhans cell histiocytosis. Thorax 2017;72:937-45.

23. Diamond EL, Subbiah V, Lockhart AC, et al. Vemurafenib for BRAF V600-Mutant Erdheim-Chester Disease and Langerhans Cell Histiocytosis: Analysis of Data From the Histology-Independent, Phase 2, Open-label VEBASKET Study. JAMA Oncol 2018;4:384-8.

(English Language Editor: J. Jones) 